\title{
Common Fixed Point Theorems in Multiplicative metric spaces using concept of CRC-self mappings
}

\author{
Sushma Devi \\ Dept. of Mathematics, Kanya Mahavidyalaya, Kharkhoda, Sonipat, India
}

Available online at: www.isroset.org

Accepted 12/Aug/2018, Online 30/Aug/2018

\begin{abstract}
In this paper, we prove common fixed point theorems using the idea of compatibility together with conditionally reciprocal continuity (CRC) in Multiplicative metric spaces.
\end{abstract}

Keywords- Common fixed point, compatible, multiplicative metric space, self-maps.

MSC: 47H10, $54 \mathrm{E} 50,54 \mathrm{H} 25$

\section{INTRODUCTION}

It is well known that $\mathrm{R}_{+}$is not complete according to the usual metric. To over come this problem, in 2008, Bashirov et al. [ 5] introduced the notion of multiplicative metric spaces and studied the concept of multiplicative calculus and proved the elementary theorem of multiplicative calculus. In Özavşar and Çevikel [16] investigate multiplicative metric spaces by remarking its topological properties, and introduced concept of multiplicative contraction mapping and proved some fixed point theorems of multiplicative contraction mappings on multiplicative spaces. Recently, He et al. [21] proved common fixed point theorems for four self-mappings in multiplicative metric space. Very recently, Abbas et ai. [2] Proved some common fixed point results of quasi-weak commutative mappings on a closed ball in the framework of multiplicative metric space. Kang et al. [10] introduced the notions of compatible mappings and its variants in multiplicative metric spaces, and proved some common fixed point theorems for these mappings. In the present paper, we established the fixed point results in the multiplicative metric spaces using compatibility and conditionally reciprocal continuity (CRC) of self-mappings.

Definition 2.1. Let $X$ be a nonempty set. Multiplicative metric is a mapping

$\mathrm{d}: \mathrm{X} \times \mathrm{X} \rightarrow \mathrm{R}^{+}$satisfying the following conditions:

(i) $\mathrm{d}(\mathrm{x}, \mathrm{y}) \geq 1$ for all $\mathrm{x}, \mathrm{y} \in \mathrm{X}$ and $\mathrm{d}(\mathrm{x}, \mathrm{y})=1$ if and only if $\mathrm{x}$ $=\mathrm{y}$,

(ii) $d(x, y)=d(y, x)$ for all $x, y \in X$,

(iii) $\mathrm{d}(\mathrm{x}, \mathrm{y}) \leq \mathrm{d}(\mathrm{x}, \mathrm{z}) \cdot \mathrm{d}(\mathrm{z}, \mathrm{y})$ for all $\mathrm{x}, \mathrm{y}, \mathrm{z} \in \mathrm{X}$ (multiplicative triangle

inequality).
Example 2.2. Let $R_{+}^{n}$ be the collection of all n-tuples of positive real numbers. Let $\mathrm{d}: R_{+}^{n} \times R_{+}^{n} \rightarrow \mathrm{R}$ be defined as $\mathrm{d}(\mathrm{x}, \mathrm{y})=\left(\left|\frac{x_{1}}{y_{1}}\right|,\left|\frac{x_{2}}{y_{2}}\right|, \ldots \ldots . .\left|\frac{x_{n}}{y_{n}}\right|\right)$, where $\mathrm{x}=\left(\mathrm{x}_{1}, \mathrm{x}_{2}, \ldots . ., \mathrm{x}_{\mathrm{n}}\right)$, $\mathrm{y}=\left(\mathrm{y}_{1}, \mathrm{y}_{2}, \ldots ., \mathrm{y}_{\mathrm{n}}\right) \in R_{+}^{n}$.

And |.|: $\mathrm{R}_{+} \rightarrow \mathrm{R}_{+}$is defined by

$|a|= \begin{cases}a & \text { if } a \geq 1 \\ \frac{1}{a} & \text { if } a<1\end{cases}$

Then it is obvious that all conditions of multiplicative metric are satisfied.

Example 2.3. Let $d: R \times R \rightarrow[1, \infty)$ be defined by $d(x, y)$ $=a^{|x-y|}$ where $x, y \in R$ and $a>1$. Then $d$ is multiplicative metric.

Example 2.4. Let $(\mathrm{X}, \mathrm{d})$ be a metric space, then the mapping $\mathrm{d}_{\mathrm{a}}$ defined on $\mathrm{X}$ as follows is multiplicative metric, $\mathrm{d}_{\mathrm{a}}(\mathrm{x}, \mathrm{y})=$ $a^{d(x, y)}$ where $a>1$ is a real number. For discrete metric $d$ the corresponding mapping $\mathrm{d}_{\mathrm{a}}$ called discrete multiplicative metric is defined as:

$\mathrm{d}_{\mathrm{a}}(\mathrm{x}, \mathrm{y})=\mathrm{a}^{\mathrm{d}(\mathrm{x}, \mathrm{y})}= \begin{cases}1 & \text { if } x=y \\ a & \text { if } x \neq y\end{cases}$

Remark2.5. Neither every metric is multiplicative metric nor every multiplicativemetric is metric.The mapping $d$ defined in example 1.2 is multiplicative metric but not metric as it doesn't satisfy triangular inequality. Consider d ( $\left.\frac{1}{3}, \frac{1}{2}\right)+\mathrm{d}\left(\frac{1}{2}, 3\right)=7.5<9=\mathrm{d}\left(\frac{1}{3}, 3\right)$. On the the other hand 
the usual metric on $\mathrm{R}$ is not multiplicative metric as it doesn't satisfy multiplicative triangular inequality. As $d(2,3) \cdot d(3,6)=3<d(2,6)$.

Definition 2.6. Let $(\mathrm{X}, \mathrm{d})$ be a multiplicative metric space. Then a sequence

$\left\{x_{n}\right\}$ in $X$ said to be

(1) a multiplicative convergent to $\mathrm{x}$ if for every multiplicative open ball

$B_{\epsilon}(\mathrm{x})=\{\mathrm{y} ; \mathrm{d}(\mathrm{x}, \mathrm{y})<\in\}, \in>1$; there exists a natural number $\mathrm{N}$ such that

$\mathrm{n} \geq \mathrm{N}$; then $\mathrm{x}_{\mathrm{n}} \in B_{\in}(\mathrm{x})$, that is, $\mathrm{d}\left(\mathrm{x}_{\mathrm{n}}, \mathrm{x}\right) \rightarrow 1$ as $\mathrm{n} \rightarrow \infty$.

(2) a multiplicative Cauchy sequence if for all $\in>1$; there exists a natural number $\mathrm{N}$ such that $\mathrm{d}\left(\mathrm{x}_{\mathrm{n}}, \mathrm{x}_{\mathrm{m}}\right)<\in$ for all $\mathrm{m}$, $\mathrm{n}>\mathrm{N}$, that is, $\mathrm{d}\left(\mathrm{x}_{\mathrm{n}}, \mathrm{x}_{\mathrm{m}}\right) \rightarrow 1$ as $\mathrm{n} \rightarrow \infty$.

(3) We call a multiplicative metric space complete if every multiplicative

Cauchy sequence in it is multiplicative convergent to $\mathrm{x} \in$ $\mathrm{X}$

Definition2.7:Let $f$ and $g$ map from a multiplicative metric space ( $\mathrm{X}, \mathrm{d}$ ) into itself. The maps $\mathrm{f}$ and $\mathrm{g}$ are said to be compatible, if for all $\mathrm{t}>0$,

$\lim _{n \rightarrow \infty}\left(d\left(f g x_{n}, g f x_{n}\right)=1\right.$

Whenever $\left\{x_{n}\right\}$ is a sequence in $X$ such that $\lim _{n \rightarrow \infty} f x_{n}=\lim _{n \rightarrow \infty}$ $\mathrm{g} \mathrm{X}_{\mathrm{n}}=\mathrm{t}$ for some $\mathrm{t} \in \mathrm{X}$.

From this definition it is inferred that $\mathrm{f}$ and $\mathrm{g}$ are noncompatible maps from a multiplicative metric space (X, d ) ito itself if $\lim _{n \rightarrow \infty} f_{x_{n}}=\lim _{n \rightarrow \infty} g x_{n}=t$ for some $t \in X$ but either $\lim _{n \rightarrow \infty}\left(d\left(\operatorname{fgx}_{\mathrm{n}}, \mathrm{gfx}_{\mathrm{n}}\right) \neq 1\right.$ or the limit does not exist.

Definition2.8 . Let $\mathrm{f}$ and $\mathrm{g}$ be two mappings of $\mathrm{a}$ multiplicative metric space $(\mathrm{X}, \mathrm{d})$ into itself. Then $\mathrm{f}$ and $\mathrm{g}$ are said to be

(i) R-weakly commuting if there exists some $\mathrm{R}>0$ such that $\mathrm{d}(\mathrm{fgx}, \mathrm{gfx}) \leq \mathrm{d}^{\mathrm{R}}(\mathrm{fx}, \mathrm{gx})$ for all $\mathrm{x} \in$ $\mathrm{X}$.

(ii) R-weakly commuting of type $\left(\mathrm{A}_{\mathrm{g}}\right)$ if there exists some $\mathrm{R}>0$ such that $\mathrm{d}(\mathrm{fgx}, \mathrm{ggx}) \leq$ $\mathrm{d}^{\mathrm{R}}(\mathrm{fx}, \mathrm{gx})$ for all $\mathrm{x} \in \mathrm{X}$.

(iii) R-weakly commuting of type $\left(\mathrm{A}_{\mathrm{f}}\right)$ if there exists some $R>0$ such that $d(f f x, g f x) \leq d^{R}(f x$, gx) for all $\mathrm{x} \in \mathrm{X}$.

Definition2.9 . A pair of self mappings ( $f, g$ ) of a multiplicative metric space $(\mathrm{X}, \mathrm{d})$ is said to be Conditionally reciprocally continuous $(\mathrm{CRC})$ if whenever set of sequences $\left\{\mathrm{x}_{\mathrm{n}}\right\}$ satisfying $\lim _{n \rightarrow \infty} \mathrm{fx}_{\mathrm{n}}=\lim _{n \rightarrow \infty} \mathrm{gx}_{\mathrm{n}}$ is non-empty, there exist a sequence $\left\{y_{n}\right\}$ satisfying $\lim _{n \rightarrow \infty} f y_{n}=\lim _{n \rightarrow \infty} g y_{n}=u$ (say) such that $\lim _{n \rightarrow \infty} \operatorname{fgy}_{\mathrm{n}}=\mathrm{fu}, \lim _{n \rightarrow \infty} \mathrm{gfy}_{\mathrm{n}}=\mathrm{gu}$.

\section{MAIN RESULTS}

Theorem 3.1. Let $\mathrm{f}$ and $\mathrm{g}$ be conditionally reciprocally continuous self-mappings of a complete multiplicative metric space $(X, d)$ satisfying the conditions :

(1) $\mathrm{f}(\mathrm{X}) \subseteq \mathrm{g}(\mathrm{X})$

(2) for any $\mathrm{x}, \mathrm{y} \in \mathrm{X}, \mathrm{t}>0$ and $\lambda \in[0,1)$ such that $\mathrm{d}(\mathrm{fx}, \mathrm{fy}) \leq \mathrm{d}(\mathrm{gx}, \mathrm{gy}) \lambda$

if $\mathrm{f}$ and $\mathrm{g}$ are either compatible or $\mathrm{g}$-compatible or $\mathrm{f}$ compatible then $\mathrm{f}$ and $\mathrm{g}$ have a unique common fixed point.

Proof. Let $\mathrm{x}_{0}$ be any point in $X$. Then as $\mathrm{f}(\mathrm{X}) \subseteq \mathrm{g}(\mathrm{X})$ there exist a sequence of points $\left\{x_{n}\right\}$ in $X$ such that $\mathrm{fx}_{n}=g x_{n+1}$. Also, define a sequence $\mathrm{y}_{\mathrm{n}}$ in $\mathrm{X}$ as

$\mathrm{y}_{\mathrm{n}}=\mathrm{fx}_{\mathrm{n}}=\mathrm{gx}_{\mathrm{n}+1}$

Now we show that $\left\{y_{n}\right\}$ is a Cauchy sequence in $X$. Consider

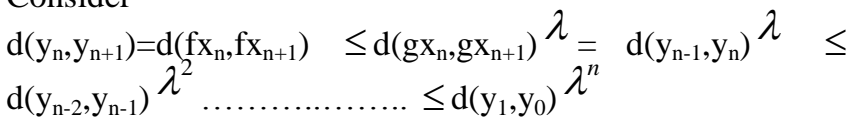
Let $m, n \in N$ such that $m>n$, then we get

$\mathrm{d}\left(\mathrm{y}_{\mathrm{m}}, \mathrm{y}_{\mathrm{n}}\right) \leq \mathrm{d}\left(\mathrm{y}_{\mathrm{m}}, \mathrm{y}_{\mathrm{m}-1}\right) \cdot \mathrm{d}\left(\mathrm{y}_{\mathrm{m}-1}, \mathrm{y}_{\mathrm{m}-2}\right) \ldots \ldots \ldots \mathrm{d}\left(\mathrm{x}_{\mathrm{n}+1}, \mathrm{x}_{\mathrm{n}}\right) \leq$ $d\left(y_{1}, y_{0}\right)^{\lambda^{m-1}+\ldots \ldots . . . \lambda^{n}}$

$$
\leq d\left(y_{1}, y_{0}\right)^{\frac{\lambda^{m}}{1-\lambda}}
$$

As $\mathrm{m}, \mathrm{n} \rightarrow \infty$ implies $\mathrm{d}\left(\mathrm{y}_{\mathrm{m}}, \mathrm{y}_{\mathrm{n}}\right) \rightarrow 1$. Hence $\left\{\mathrm{y}_{\mathrm{n}}\right\}$ is a Cauchy sequence in $\mathrm{X}$. But $\mathrm{X}$ is complete multiplicative metric space, there is $z \in X$ such that $\lim _{n \rightarrow \infty} y_{n}=z$. Moreover

$\lim _{n \rightarrow \infty} y_{n}=\lim _{n \rightarrow \infty} f_{x}=\lim _{n \rightarrow \infty} g_{n+1}=z$.

Since $f$ and $g$ are Conditionally reciprocally continuous $(C R C)$ and $\lim _{n \rightarrow \infty} \mathrm{fx}_{\mathrm{n}}=\lim _{n \rightarrow \infty} \mathrm{gx}_{\mathrm{n}+1}=\mathrm{z}$, there exist a sequence $\left\{z_{n}\right\}$ satisfies $\lim _{n \rightarrow \infty} f z_{n}=\lim _{n \rightarrow \infty} g z_{n}=z$ such that $\lim _{n \rightarrow \infty}$ $f g z_{n}=f z$ and $\lim _{n \rightarrow \infty} g f z_{n}=g z$.

Since $\mathrm{f}(\mathrm{X}) \subseteq \mathrm{g}(\mathrm{X})$, for each $\mathrm{z}_{\mathrm{n}}$ there exist $\mathrm{s}_{\mathrm{n}} \in \mathrm{X}$ such that $\mathrm{f}\left(\mathrm{z}_{\mathrm{n}}\right)=\mathrm{g}\left(\mathrm{s}_{\mathrm{n}}\right)$ Thus 
$\lim _{n \rightarrow \infty} \mathrm{fz}_{\mathrm{n}}=\lim _{n \rightarrow \infty} \mathrm{gs}_{\mathrm{n}}=\lim _{n \rightarrow \infty} \mathrm{gz_{ \textrm {n } }}=\mathrm{z}, \mathrm{d}\left(\mathrm{f}\left(\mathrm{s}_{\mathrm{n}}\right), \mathrm{f}\left(\mathrm{z}_{\mathrm{n}}\right)\right) \leq \mathrm{d}\left(\mathrm{gs}_{\mathrm{n}}, \mathrm{gz}_{\mathrm{n}}\right)$

. Taking limit $\mathrm{n} \rightarrow \infty$, we have

$\mathrm{d}\left(\lim _{n \rightarrow \infty} \mathrm{f}\left(\mathrm{s}_{\mathrm{n}}\right), \mathrm{z}\right) \leq \mathrm{d}(\mathrm{z}, \mathrm{z})^{\lambda}=1$

Thus $\mathrm{z}=\lim _{n \rightarrow \infty} \mathrm{fs}_{\mathrm{n}}$

Since $f$ and $g$ are compatible mapping. Then $\lim _{n \rightarrow \infty} d\left(f g z_{n}\right.$, $\left.\mathrm{gfz}_{\mathrm{n}}\right)=1$ i.e

$\lim _{n \rightarrow \infty} f g z_{n}=\lim _{n \rightarrow \infty} g f z_{n}$ thus fz=gz. Also, fgz=ffz=fgz=gfz. Now

$\mathrm{d}(\mathrm{fz}, \mathrm{ffz}) \leq d(g z, g f z)^{\lambda}=d(f z, f f z)^{\lambda} \leq d(f z, f f z)$

that is $\mathrm{fz}=\mathrm{ff} z$. Hence $\mathrm{fz}=\mathrm{ffz}=\mathrm{gfz}$ and $\mathrm{fz}$ is a common fixed point of $f$ and $g$.

Now, suppose that $\mathrm{f}$ and $\mathrm{g}$ are $\mathrm{g}$-compatible mappings . then

$\lim _{n \rightarrow \infty} d\left(f f s_{n}, g f s_{n}, t\right)=1 \quad$ that is

$\lim _{n \rightarrow \infty} f f s_{n}=\lim _{n \rightarrow \infty} g f s_{n}=g z$. Now, we get d(fz,ffs $\left.\mathrm{f}_{\mathrm{n}}\right)$

$\leq d\left(g z, g f s_{n}\right)^{\lambda}$ taking limit as $\mathrm{n} \rightarrow \infty$, we get $\mathrm{d}(\mathrm{fz}, \mathrm{gz})$

$\leq d(g z, g z)^{\lambda}=1$

This gives , $\mathrm{fz}=\mathrm{gz}$. Also, $\mathrm{fgz}=\mathrm{ff} \mathrm{f}=\mathrm{fgz}=\mathrm{gfz}$. Thus

$\mathrm{d}(\mathrm{fz}, \mathrm{ffz}) \leq d(g z, g f z)^{\lambda}=d(f z, f f z)^{\lambda} \leq d(f z, f f z)$

that is $f z=f f z$. Hence $f z=f f z=g f z$ and $f z$ is a common fixed point of $f$ and $g$.

Finally, suppose that $\mathrm{f}$ and $\mathrm{g}$ are $\mathrm{f}$-compatible mappings. then $\quad \lim _{n \rightarrow \infty} d\left(f g s_{n}, g g s_{n}, t\right)=1 \quad$ that is, $\lim _{n \rightarrow \infty} f g s_{n}=\lim _{n \rightarrow \infty} g g s_{n}=g z$. Now, we get $\mathrm{d}\left(\mathrm{fz}, \mathrm{fgs}_{\mathrm{n}}\right)$ $\leq d\left(g z, g g s_{n}\right)^{\lambda}$ taking limit as $\mathrm{n} \rightarrow \infty$, we get $\mathrm{d}(\mathrm{fz}, \mathrm{gz})$ $\leq d(g z, g z)^{\lambda}=1$

This gives $f z=g z$. Hence $f g z=f f z=g f z=f g z$. Thus

$\mathrm{d}(\mathrm{fz}, \mathrm{ffz}) \leq d(g z, g f z)^{\lambda}=d(f z, f f z)^{\lambda} \leq d(f z, f f z)$

that is $f z=f f z$. Hence $f z=f f z=g f z$ and $f z$ is a common fixed point of $f$ and $g$.
Uniqueness of common fixed point theorem follows easily in each cases.

Theorem 3.2. Let $\mathrm{f}$ and $\mathrm{g}$ be conditionally reciprocally continuous self-mappings of a complete multiplicative metric space $(X, d)$ satisfying the conditions :

(1) $\mathrm{f}(\mathrm{X}) \subseteq \mathrm{g}(\mathrm{X})$

(2) for any $\mathrm{x}, \mathrm{y} \in \mathrm{X}$ and $\lambda \in[0,1)$ such that $\mathrm{d}(\mathrm{fx}, \mathrm{fy}) \leq$ $\mathrm{d}(\mathrm{gx}, \mathrm{gy}) \lambda$

(3) for any $\mathrm{x} \in \mathrm{X}$ and $\lambda \in[0,1) \mathrm{d}(\mathrm{fx}, \mathrm{ffx}) \leq \mathrm{d}(\mathrm{gx}, \mathrm{ggx})$ $\lambda$ whenever gx $\neq$ ggx

if $f$ and $g$ are non- compatible but either g-compatible or $f$ compatible then $\mathrm{f}$ and $\mathrm{g}$ have a common fixed point.

Proof.Since $\mathrm{f}$ and $\mathrm{g}$ are non-compatible maps, there exists a sequence $\left\{\mathrm{x}_{\mathrm{n}}\right\}$ in $\mathrm{X}$ such that $\mathrm{fx}_{\mathrm{n}} \rightarrow \mathrm{z}$ and $\mathrm{fx}_{\mathrm{n}} \rightarrow \mathrm{z}$ for some $\mathrm{z} \in \mathrm{X}$ as $\mathrm{n} \rightarrow \infty$ but either $\lim _{n \rightarrow \infty} \mathrm{d}\left(\mathrm{fgx}_{\mathrm{n}}, \mathrm{gfx}_{\mathrm{n}}\right) \neq 1$ or the limit does not exist. Also since $\mathrm{f}$ and $\mathrm{g}$ are Conditionally reciprocally continuous(CRC) and $\lim _{n \rightarrow \infty} \mathrm{fx}_{\mathrm{n}}=\lim _{n \rightarrow \infty} \mathrm{gx}_{\mathrm{n}}=\mathrm{z}$, there exist a sequence $\left\{\mathrm{z}_{\mathrm{n}}\right\}$ satisfies $\lim _{n \rightarrow \infty} \mathrm{fz}_{\mathrm{n}}=\lim _{n \rightarrow \infty} \mathrm{gz_{ \textrm {n } }}=\mathrm{z}$ such that $\lim _{n \rightarrow \infty} \mathrm{fgz}_{\mathrm{n}}=\mathrm{fz}$ and $\lim _{n \rightarrow \infty} \mathrm{gfz}_{\mathrm{n}}=\mathrm{gz}$.

Since $\mathrm{f}(\mathrm{X}) \subseteq \mathrm{g}(\mathrm{X})$, for each $\mathrm{z}_{\mathrm{n}}$ there exist $\mathrm{s}_{\mathrm{n}} \in \mathrm{X}$ such that $\mathrm{f}\left(\mathrm{z}_{\mathrm{n}}\right)=\mathrm{g}\left(\mathrm{s}_{\mathrm{n}}\right)$ Thus

$\lim _{n \rightarrow \infty} \mathrm{fz}_{\mathrm{n}}=\lim _{n \rightarrow \infty} \mathrm{gs}_{\mathrm{n}}=\lim _{n \rightarrow \infty} \mathrm{gz}_{\mathrm{n}}=\mathrm{z}$, Also, $\mathrm{d}\left(\mathrm{f}\left(\mathrm{s}_{\mathrm{n}}\right), \mathrm{f}\left(\mathrm{z}_{\mathrm{n}}\right)\right) \leq \mathrm{d}\left(\mathrm{gs}_{\mathrm{n}}\right.$ $\left.\mathrm{gz}_{\mathrm{n}}\right)^{\lambda}$. Taking limit $\mathrm{n} \rightarrow \infty$, we have

$\mathrm{d}\left(\lim _{n \rightarrow \infty} \mathrm{f}\left(\mathrm{s}_{\mathrm{n}}\right), \mathrm{z}\right) \leq \mathrm{d}(\mathrm{z}, \mathrm{z})^{\lambda}=1$

Thus $\mathrm{z}=\lim _{n \rightarrow \infty} \mathrm{fs}_{\mathrm{n}}$. Therefore we have $\lim _{n \rightarrow \infty} \mathrm{fz}_{\mathrm{n}}=\lim _{n \rightarrow \infty} \mathrm{gz}_{\mathrm{n}}=$ $\lim _{n \rightarrow \infty} \mathrm{gs}_{\mathrm{n}}=\lim _{n \rightarrow \infty} \mathrm{fs}_{\mathrm{n}}=\mathrm{z}$.

Now, suppose that $\mathrm{f}$ and $\mathrm{g}$ are g-compatible mappings . then $\lim _{n \rightarrow \infty} d\left(f f s_{n}, g f s_{n}, t\right)=1 \quad$ that is, $\lim _{n \rightarrow \infty} f f s_{n}=\lim _{n \rightarrow \infty} g f s_{n}=g z$. Now, we get d(fz,ffs $\left.\mathrm{fs}_{\mathrm{n}}\right)$ $\leq d\left(g z, g f s_{n}\right)^{\lambda}$ taking limit as $\mathrm{n} \rightarrow \infty$, we get $\mathrm{d}(\mathrm{fz}, \mathrm{gz})$ $\leq d(g z, g z)^{\lambda}=1$

This gives, $\mathrm{fz}=\mathrm{gz}$. Also, $\mathrm{fgz}=\mathrm{ff} \mathrm{z}=\mathrm{fgz}=\mathrm{gfz}$. Thus

$\mathrm{d}(\mathrm{fz}, \mathrm{ffz}) \leq d(g z, g f z)^{\lambda}=d(f z, f f z)^{\lambda} \leq d(f z, f f z)$ 
that is $f z=f f z$. Hence $f z=f f z=g f z$ and $f z$ is a common fixed point of $f$ and $g$.

Finally, suppose that $\mathrm{f}$ and $\mathrm{g}$ are f-compatible mappings . then $\quad \lim _{n \rightarrow \infty} d\left(f g s_{n}, g g s_{n}, t\right)=1 \quad$ that is, $\lim _{n \rightarrow \infty} f g s_{n}=\lim _{n \rightarrow \infty} g g s_{n}=g z$. Now, we get $\mathrm{d}\left(\mathrm{fz}, \mathrm{fgs}_{\mathrm{n}}\right)$ $\leq d\left(g z, g g s_{n}\right)^{\lambda}$ taking limit as $\mathrm{n} \rightarrow \infty$, we get $\mathrm{d}(\mathrm{fz}, \mathrm{gz})$ $\leq d(g z, g z)^{\lambda}=1$

This gives $f z=g z$. Hence $f g z=f f z=g f z=f g z$. Thus

$\mathrm{d}(\mathrm{fz}, \mathrm{ffz}) \leq d(g z, g f z)^{\lambda}=d(f z, f f z)^{\lambda} \leq d(f z, f f z)$

that is $f z=f f z$. Hence $f z=f f z=g f z$ and $f z$ is a common fixed point of $f$ and $g$.

Theorem 3.3. . Let $f$ and $g$ be conditionally reciprocally continuous self-mappings of a complete multiplicative metric space $(X, d)$ satisfying the conditions :

(1) $\mathrm{f}(\mathrm{X}) \subseteq \mathrm{g}(\mathrm{X})$

(2) for any $x, y \in X$ such that $d(f x, f y) \leq d(g x, g y)$

(3) for any $x \in X d(f x, f f x) \leq d(g x, g g x)$ whenever gx $\neq$ ggx

if $\mathrm{f}$ and $\mathrm{g}$ are non- compatible but either $\mathrm{g}$-compatible or $\mathrm{f}$ compatible then $\mathrm{f}$ and $\mathrm{g}$ have a common fixed point.

Proof.Since $f$ and $g$ are non-compatible maps, there exists a sequence $\left\{\mathrm{x}_{\mathrm{n}}\right\}$ in $\mathrm{X}$ such that $\mathrm{fx}_{\mathrm{n}} \rightarrow \mathrm{z}$ and $\mathrm{fx}_{\mathrm{n}} \rightarrow \mathrm{z}$ for some $\mathrm{z} \in \mathrm{X}$ as $\mathrm{n} \rightarrow \infty$ but either $\lim _{n \rightarrow \infty} \mathrm{d}\left(\mathrm{fgx}_{\mathrm{n}}, \mathrm{gfx}_{\mathrm{n}}\right) \neq 1$ or the limit does not exist. Also since $\mathrm{f}$ and $\mathrm{g}$ are Conditionally reciprocally continuous(CRC) and $\lim _{n \rightarrow \infty} \mathrm{fx}_{\mathrm{n}}=\lim _{n \rightarrow \infty} \mathrm{gx}_{\mathrm{n}}=\mathrm{z}$, there exist a sequence $\left\{\mathrm{z}_{\mathrm{n}}\right\}$ satisfies $\lim _{n \rightarrow \infty} \mathrm{fz}_{\mathrm{n}}=\lim _{n \rightarrow \infty} \mathrm{gz}_{\mathrm{n}}=\mathrm{z}$ such that $\lim _{n \rightarrow \infty} \mathrm{fgz}_{\mathrm{n}}=\mathrm{fz}$ and $\lim _{n \rightarrow \infty} \mathrm{gfz}_{\mathrm{n}}=\mathrm{gz}$.

Since $f(X) \subseteq g(X)$, for each $z_{n}$ there exist $s_{n} \in X$ such that $\mathrm{f}\left(\mathrm{z}_{\mathrm{n}}\right)=\mathrm{g}\left(\mathrm{s}_{\mathrm{n}}\right)$ Thus

$\lim _{n \rightarrow \infty} \mathrm{fz}_{\mathrm{n}}=\lim _{n \rightarrow \infty} \mathrm{gs}_{\mathrm{n}}=\lim _{n \rightarrow \infty} \mathrm{gz}_{\mathrm{n}}=\mathrm{z}$, Also, $\mathrm{d}\left(\mathrm{f}\left(\mathrm{s}_{\mathrm{n}}\right), \mathrm{f}\left(\mathrm{z}_{\mathrm{n}}\right)\right) \leq \mathrm{d}\left(\mathrm{gs}_{\mathrm{n}}\right.$ , $\mathrm{gz}_{\mathrm{n}}$ ). Taking limit $\mathrm{n} \rightarrow \infty$, we have

$\mathrm{d}\left(\lim _{n \rightarrow \infty} \mathrm{f}\left(\mathrm{s}_{\mathrm{n}}\right), \mathrm{z}\right) \leq \mathrm{d}(\mathrm{z}, \mathrm{z})=1$

Thus $\mathrm{z}=\lim _{n \rightarrow \infty} \mathrm{fs}_{\mathrm{n}}$. Therefore we have $\lim _{n \rightarrow \infty} \mathrm{fz}_{\mathrm{n}}=\lim _{n \rightarrow \infty} \mathrm{gz}_{\mathrm{n}}=$ $\lim _{n \rightarrow \infty} \mathrm{gs}_{\mathrm{n}}=\lim _{n \rightarrow \infty} \mathrm{fs}_{\mathrm{n}}=\mathrm{z}$.
Now, suppose that $\mathrm{f}$ and $\mathrm{g}$ are $\mathrm{g}$-compatible mappings . then $\lim _{n \rightarrow \infty} d\left(f f s_{n}, g f s_{n}, t\right)=1 \quad$ that is, $\lim _{n \rightarrow \infty} f f s_{n}=\lim _{n \rightarrow \infty} g f s_{n}=g z$. Now, we get d(fz,ffs $\left.\mathrm{fs}_{\mathrm{n}}\right)$ $\leq d\left(g z, g f s_{n}\right)$ taking limit as $\mathrm{n} \rightarrow \infty$, we get $\mathrm{d}(\mathrm{fz}, \mathrm{gz})$ $\leq d(g z, g z)=1$

This gives , $f z=g z$. Also, $f g z=f f z=f g z=g f z$. Thus $\mathrm{d}(\mathrm{fz}, \mathrm{ffz}) \leq d(g z, g f z)=d(f z, f f z) \leq d(f z, f f z)$

that is $f z=f f z$. Hence $f z=f f z=g f z$ and $f z$ is a common fixed point of $f$ and $g$.

Finally, suppose that $\mathrm{f}$ and $\mathrm{g}$ are $\mathrm{f}$-compatible mappings . then $\quad \lim _{n \rightarrow \infty} d\left(f g s_{n}, g g s_{n}, t\right)=1 \quad$ that is, $\lim _{n \rightarrow \infty} f g s_{n}=\lim _{n \rightarrow \infty} g g s_{n}=g z$. Now, we get $\mathrm{d}\left(\mathrm{fz}, \mathrm{fgs}_{\mathrm{n}}\right)$ $\leq d\left(g z, g g s_{n}\right)$ taking limit as $\mathrm{n} \rightarrow \infty$, we get $\mathrm{d}(\mathrm{fz}, \mathrm{gz})$ $\leq d(g z, g z)=1$

This gives $f z=g z$. Hence $f g z=f f z=g f z=f g z$. Thus

$\mathrm{d}(\mathrm{fz}, \mathrm{ffz}) \leq d(g z, g f z)=d(f z, f f z) \leq d(f z, f f z)$

that is $f z=f f z$. Hence $f z=f f z=g f z$ and $f z$ is a common fixed point of $f$ and $g$.

\section{CONCLUSION}

As an application of CRC, we proved common fixed point theorems that extend the scope of study of common fixed point theorems from the class of compatible continuous mappings to a wider class of mappings which also includes non-compatible.

\section{ACKNOWLEDGEMENT}

The author is grateful to the "University Grants Commission (UGC)" for financial support.

\section{REFERENCES}

[1] A.E. Bashirov, E.M. Kurplnara, A. Ozyapici, Multiplicative calculus and its applications, J. Math. Anal. Appl., 337 (2008), 36-48. doi:0.1016/j.jmaa.2007.03.081

[2] Abbas M, Ali B, Suleiman YI. Common fixed points of locally contractive mappings in multiplicative metric spaces with application. Int. J. Math. Math. Sci. 2015;7. Article ID 18683.Available:http://dx.doi.org/10.1155/2015/218683

[3] Abdou AAN. Fixed point theorems for generalized contraction mappings in multiplicative metricspaces. J. Nonlinear Sci. Appl. 2016;9:2347-2363. 
[4] Abodayeh K, Pitea A, Shatanawi W, Abdeljawad T. Remarks on multiplicative metric spaces andrelated fixed points. Arxiv: 1512.03771v1 [math.GN]; 2015.Available:http:// dx.doi.org/10.1186/1687-1812-2014-48

[5] Bashirov AE, Kurplnara EM, Ozyapici A. Multiplicative calculus and its applications, J. Math. Anal. Appl. 2008;337:36-48.

[6] Bashirov AE, Misirli E, Tandogdu Y, Ozyapici A. On modelling with multiplicative differential equations. Applied Mathematics-A Journal of Chinese Universities. 2011;26:425-438.

[7] F. Gu, L.M. Cui, Y.H. Wu, Some fixed point theorems for new contractive type mappings, J. Qiqihar Univ., 19 (2013), 85-89.

[8] He X, Song M, Chen D. Common fixed points for weak commutative mappings on a multiplicative metric space, Fixed Point Theory Appl. 2014;48:9.

[9] J.S.Kushwah, Weak compatible and reciprocally continuous maps in Non-Archimedean Menger PM-Space, IJSRMSS, Vol.3 (2),2016 p 9 12.

[10] Kang SM, Kumar P, Kumar S, Nagpal P, Garg SK. Common fixed points for compatible mappings and its variants in multiplicative metric spaces. Int. J. Pure Appl. Math. 2015;102:383-406. DOI: 10.12732/ijpam.v102i2.14

[11] Kang SM, Nagpal P, Garg SK, Kumar S. Fixed points for multiplicative expansive mappings in multiplicative metric spaces. International Journal of Mathematical Analysis. 2015;9(39):19391946.

[12] M. "Ozavsar, A.C. Cevikel, Fixed point of multiplicative contraction mappings on multiplicative metric space, arXiv:1205.5131v1 [matn.GM], 2012.

[13] M. Sarwar, R. Badshah-e, Some unique fixed point theorems in multiplicative metric space, arXiv:1410.3384v2 [math.GM], 2014 Available:http://dx.doi.org/10.12988/ijma. 2015.54130.

[14] Muhammad Sarwar. Badshah-e-Rome: Some unique fixed point theorems in multiplicative metric spaces, arXiv: $1410.3384 \mathrm{v} 2$ [math.GM];2014.

[15] Nagpal P, Kang SM, Garg SK, Kumar S. Several fixed point theorems for expansive mappings in multiplicative metric spaces. Int. J. Pure Appl. Math. 2016;107(2):357-369.Available: http://www.ijpam.euDOI: 10.12732/ Ijpam.V10 7i2.6

[16] Ozavsar M, Cervikel AC. Fixed points of multiplicative contraction mappings on multiplicative metric spaces. [math.GM]; 2012. Available: http://arxiv.org/abs/ 1205.5131v1

[17] Ravi P. Agarwal, Erdal Karapınar, Bessem Samet. An essential remark on fixed point results on multiplicative metric spaces. Fixed Point Theory and Applications. 2016;1(2016):1-3.

[18] S.M.King, P.Kumar, S.Kumar, P.Nagpal and S.Garg, Common fixed points for compatible mappings and its variants in multiplicative metric spaces, I. J of Pure and Applied mathematics, 102(2) 2015, 383-406.

[19] Sessa S. On a weak commutativity condition of mappings in fixed point considerations. InstitutMath'ematique. 1982;32:149-153.

[20] Sukh raj S., Manoj U., R.D.Daheriya, Rashmi J.and Suraj S., Coincidence point \& common fixed points for multiplicative expansive type mappings, British journal of mathematics \& computer science 19(3), 1-14, 2016.

[21] X. He, M. Song, D. Chen, Common fixed points for weak commutative mappings on a multiplicative metric space, Fixed Point Theory Appl., 48(2014), 9 pages. doi: 10.1186/1687-1812-2014-48. 